\title{
PERTURBATION OF BENZODIAZEPINE RECEPTOR BINDING BY PYRAZOLOPYRIDINES INVOLVES PICROTOXININ/BARBITURATE RECEPTOR SITES ${ }^{1}$
}

\author{
FREDRIK LEEB-LUNDBERG, ADELE SNOWMAN, AND RICHARD W. OLSEN
}

Division of Biomedical Sciences and Department of Biochemistry, University of California, Riverside, California 92521

\begin{abstract}
The two pyrazolopyridines, etazolate (SQ20009) and cartazolate (SQ65396), enhance the binding of $\left[{ }^{3} \mathrm{H}\right]$ diazepam to benzodiazepine receptor sites in rat brain. This enhancement is due to a change in affinity without a change in maximal binding. Pentobarbital also enhances $\left[{ }^{3} \mathrm{H}\right]$ diazepam binding by lowering the $K_{D}$ (Leeb-Lundberg, F., A. Snowman, and R. W. Olsen (1980) Proc. Natl. Acad. Sci. U. S. A. 77: 7468-7472). Pentobarbital gives a maximal enhancement of benzodiazepine binding slightly greater than that induced by etazolate, but maximal concentrations of etazolate cannot increase further the maximal enhancement by pentobarbital. By contrast, the enhancement of benzodiazepine binding by $\gamma$-aminobutyric acid (GABA) is fully additive with the effect of either etazolate or pentobarbital. The enhancement by $\gamma$-aminobutyric acid is blocked specifically by the two $\gamma$-aminobutyric acid mimetic compounds, imidazole acetic acid and 4,5,6,7-tetrahydroisoxazolo[5,4-c]pyridin-3-ol (THIP), compounds which do not inhibit the enhancement of diazepam binding by pentobarbital or etazolate. The effects of etazolate and pentobarbital, but not those of GABA, can be blocked competitively by 1 to $10 \mu \mathrm{M}$ picrotoxinin. Etazolate and cartazolate, like pentobarbital (Ticku, M. K., M. Ban, and R. W. Olsen (1978) Mol. Pharmacol. 14: 391-402), competitively inhibit $\alpha-\left[{ }^{3} \mathrm{H}\right]$ dihydropicrotoxinin binding with potencies correlating well with their stimulatory properties on benzodiazepine binding. These results suggest that pyrazolopyridines, like pentobarbital, stimulate $\left[{ }^{3} \mathrm{H}\right]$ diazepam binding through a picrotoxinin-sensitive site which is distinct from the $\gamma$-aminobutyric acid receptor site. These in vitro interactions between the etazolate and benzodiazepine receptor sites can be modulated also by the GABA antagonist, bicuculline, consistent with the existence of a complex containing three receptors (GABA, benzodiazepines, and etazolate/ barbiturates/picrotoxinin). Bicuculline reverses completely the effects of etazolate and GABA on benzodiazepine binding but reverses only partially the enhancement by pentobarbital. This difference between the effects of pentobarbital and etazolate, as well as differences in their maximal enhancing effects mentioned above, suggests that pentobarbital may have an action similar to etazolate on some bicuculline-sensitive benzodiazepine binding sites, but, in addition, pentobarbital can enhance some other benzodiazepine sites in a manner which is neither mimicked by etazolate nor blocked by bicuculline.
\end{abstract}

Significant evidence now exists for pharmacologically relevant benzodiazepine receptors in the mammalian central nervous system (CNS). Correlation has been made between the potency of a series of benzodiazepine compounds, such as muscle relaxants, anxiolytics, and anticonvulsants, and their affinity for the "receptor" binding sites (Squires and Braestrup, 1977; Möhler and Okada, 1977). These binding sites can be modulated by $\gamma$-aminobutyric acid (GABA) receptor agonists (Tallman et al., 1980), an effect which further increases the physiological

1 This work was supported by National Science Foundation Grant BNS 77-24414, National Institutes of Health Grants NS 12422, RR 09070, and AM 07310, and Research Career Development Award NS 00224 (to R. W. O.). significance of these receptors, since the coupling of benzodiazepine and GABA binding sites in vitro is consistent with neuropharmacological evidence that benzodiazepine action in vivo appears to involve a potentiation of GABAergic inhibitory synaptic transmission (Haefely et al., 1979; Costa and Guidotti, 1979; Tallman et al., 1980). Recently, several other agents have been reported to modulate benzodiazepine binding. For example, chloride ions modulate benzodiazepine binding (Costa et al., 1979), suggesting that the GABA receptor-coupled chloride ion channel might be involved in the binding site of benzodiazepines. Furthermore, the anxiolytic pyrazolopyridines, etazolate, cartazolate (Beer et al., 1978; Williams and Risley, 1979), and tracazolate (ICI 136,753; Salama and Meiners, 1980), as well as anesthetic barbi- 
turates (Leeb-Lundberg et al., 1980), modulate benzodiazepine binding. These effects are dependent on chloride and other anions able to penetrate GABA-activated ion channels (Supavilai and Karobath, 1979; Leeb-Lundberg et al., 1980). All of these agents are able to enhance the affinity of the benzodiazepine receptor for its ligands. We recently have characterized barbiturate enhancement in some detail and suggest that these drugs act at a picrotoxinin-sensitive site (Leeb-Lundberg et al., 1980). This study further examines the effects of pyrazolopyridines on benzodiazepine binding and their relationship to the other modulators. Our results indicate that one of the primary sites of action in the CNS for these drugs is the picrotoxinin binding site. This would further support the existence of a CNS depressant drug receptor site related to the GABA-regulated chloride ion channel.

\section{Materials and Methods}

$N$ - $\left[\right.$ methyl- $\left.{ }^{3} \mathrm{H}\right]$ Diazepam $(83.5 \mathrm{Ci} / \mathrm{mmol})$ was pur chased from New England Nuclear and $\alpha-\left[{ }^{3} \mathrm{H}\right]$ dihydropicrotoxinin (DHP, $15 \mathrm{Ci} / \mathrm{mmol}$ ) was custom synthesized by Amersham. Benzodiazepines were kindly donated by Dr. H. Möhler and Dr. W. Schlosser of Hoffmann-La Roche. Etazolate (SQ20009) and cartazolate (SQ65396) were gifts of E. R. Squibb \& Sons, Inc. TETS (tetramethylenedisulfotetramine) was the gift of Dr. J. Casida, Berkeley, CA. Picrotoxinin was obtained from picrotoxin (Sigma) by column chromatography. Dihydropicrotoxinin was obtained from picrotoxinin by reduction under $\mathrm{H}_{2}$ gas with $\mathrm{Pt} / \mathrm{C}(5 \%)$ as a catalyst, as previously described (Ticku et al., 1978). 'THIP (4,5,6,7-tetrahydroisoxazolo[5,4-c]pyridin-3-ol) was a gift of Dr. P. Krogsgaard-Larsen, Copenhagen. All other materials were obtained from commercial sources.

White Sprague-Dawley rats $(200$ to $300 \mathrm{gm})$ were decapitated and their brains were removed rapidly and bathed in ice cold $0.32 \mathrm{M}$ sucrose. Cerebral cortex then was homogenized in $20 \mathrm{vol}$ of $0.32 \mathrm{M}$ sucrose in a glass homogenizer fitted with a Teflon pestle (12 passes, 400 $\mathrm{rpm}$ ). The homogenate was centrifuged at $2000 \mathrm{rpm}$ (1000 $\times g$ ) for $10 \mathrm{~min}$ at 0 to $4^{\circ} \mathrm{C}$ (Beckman JA 17 rotor). The pellet $\left(P_{1}\right)$ was discarded, and the supernatant fraction was centrifuged at $45,000 \mathrm{rpm}(140,000 \times \mathrm{g})$ for $45 \mathrm{~min}$ (Spinco rotor $60 \mathrm{Ti}$ ). The pellet $\left(\mathbf{P}_{2}+\mathbf{P}_{3}\right)$ then was treated in two different ways, depending on the binding assay to be done. Membranes for DHP binding were homogenized in ice cold buffer $(0.2 \mathrm{M} \mathrm{NaCl}, 20 \mathrm{~mm}$ sodium phosphate, $\mathrm{pH} 7.0 \pm 0.1$ ) using the glass homogenizer and centrifuged at 45,000 rpm for $15 \mathrm{~min}$. The $\mathrm{P}_{2}$ $+\mathrm{P}_{3}$ pellet was resuspended to a final concentration of 2 to $3 \mathrm{mg} / \mathrm{ml}$ of protein in the same buffer. Membranes for diazepam binding were homogenized (Ultra-Turrax tissue disrupter; $5 \mathrm{sec}$ at $40 \%$ ) in $25 \mathrm{vol}$ of ice cold double distilled water (osmotic shock) and centrifuged at 45,000 rpm for $45 \mathrm{~min}$. The pellet was washed again in buffer. This additional procedure is intended to lower membrane GABA content below the micromolar concentrations which affect benzodiazepine binding (Tallman et al., 1980), while minimizing damage to the fragile binding sites for picrotoxinin and barbiturates (Ticku et al., 1978). In some cases, where indicated, the membranes were treated further by a freeze-thaw, multiple wash procedure to remove thoroughly endogenous GABA (Napias et al., 1980; Karobath et al., 1979). The pellets were resuspended to a final protein concentration of 0.5 to $2.0 \mathrm{mg} /$ $\mathrm{ml}$ in $0.2 \mathrm{M} \mathrm{NaCl}, 20 \mathrm{~mm}$ sodium phosphate, $\mathrm{pH} 7.0$.

$D H P$ binding. Aliquots of the membrane suspension were incubated in quadruplicate for $15 \mathrm{~min}$ at $0^{\circ} \mathrm{C}$ with $50 \mathrm{nM}\left[{ }^{3} \mathrm{H}\right] \mathrm{DHP}$ with and without drugs in a total volume of $1 \mathrm{ml}$. At the end of the incubation, the membranes were pelleted rapidly $(20,000 \mathrm{rpm}$ in Beckman rotor JA $20.1 ; 50,000 \times g)$, and the vials were rinsed twice with 3 $\mathrm{ml}$ of ice cold buffer without disturbing the pellet. The membranes were solubilized overnight at room temperature in $0.2 \mathrm{ml}$ of Soluene 350:toluene (1:1). Then $3 \mathrm{ml}$ of toluene containing $0.5 \%$ 2,5-diphenyloxazole (PPO) were added and radioactivity was measured in a Beckman model LS-3155T scintillation counter (efficiency 30\%). Background was estimated with $0.1 \mathrm{~mm}$ nonradioactive DHP and contributed about $75 \%$ of the radioactivity.

$\left[{ }^{3} H\right]$ Diazepam binding. Aliquots of the membrane suspension were incubated in triplicate for $60 \mathrm{~min}$ at $0^{\circ} \mathrm{C}$ with $0.5 \mathrm{~nm}\left[{ }^{3} \mathrm{H}\right]$ diazepam with and without drugs in a total volume of $1 \mathrm{ml}$. At the end of the incubation, the membranes were trapped rapidly on Whatman GF/B filters. An additional $2 \mathrm{ml}$ of saline $(0.2 \mathrm{M} \mathrm{NaCl})$ were added twice to the vial and poured onto the filter. The filters were dried and put into plastic vials. Five milliliters of Aquasol:toluene (2:1) (New England Nuclear) were added, and radioactivity was determined as above (efficiency $45 \%$ ). Background was estimated with $10 \mu \mathrm{M}$ nonradioactive diazepam and normally contributed about $10 \%$ of the total radioactivity.

\section{Results}

The anxiolytic pyrazolopyridine compound, etazolate, markedly enhanced the specific binding of $\left[{ }^{3} \mathrm{H}\right]$ diazepam. At a single constant concentration of $\left[{ }^{3} \mathrm{H}\right]$ diazepam, etazolate increased binding up to a maximal $82 \%$ over base line, that is, $182 \%$ of control (average $75 \pm 10 \%, n=7$ ) at $10 \mu \mathrm{m}$ etazolate and a half-maximal effect at $1 \mu \mathrm{m}$ (Table I A); concentrations over $10 \mu \mathrm{M}$ gave less enhancement.

Pentobarbital and related barbiturates also enhance benzodiazepine binding in vitro (Leeb-Lundberg et al., 1980). Pentobarbital enhancement of $\left[{ }^{3} \mathrm{H}\right]$ diazepam binding in the absence and presence of etazolate $(10 \mu \mathrm{M})$ is shown in Figure 1. The maximal effect of pentobarbital was roughly $120 \%(115 \pm 10 \%, n=10)$ increase over base line, with no downturn in the enhancement even up to 3 mM pentobarbital. The maximal effect of pentobarbital was consistently somewhat greater than that of etazolate, but the stimulation by maximal concentrations of both drugs added together did not exceed that of pentobarbital alone. This suggests that the two agents may act via a common mechanism, at least in part.

The inhibitory neurotransmitter, GABA, also enhances the binding of benzodiazepines in vitro (Tallman et al., 1980). If, however, a maximal concentration of GABA $(10 \mu \mathrm{M}$, enhancement $75 \%$; Table $I B)$ was added together with a maximal concentration of etazolate (10 $\mu \mathrm{M}$, enhancement $68 \%$ ), the effect was additive $(128 \%$ enhancement). Likewise, the effect of pentobarbital (100 
TABLE I

Interaction of various drugs with pyrazolopyridine and barbiturate enhancement of benzodiazepine binding

Rat brain membranes were prepared and assayed for $\left[{ }^{3} \mathrm{H}\right]$ diazepam binding as described under "Materials and Methods" using $0.5 \mathrm{nM}$ $\left[{ }^{3} \mathrm{H}\right]$ diazepam. Each value is typical of at least two determinations in triplicate which varied by $<10 \%$. The names and sources of all drugs are given in the text.

\begin{tabular}{|c|c|c|}
\hline & Additions & $\begin{array}{c}{\left[{ }^{3} \text { H]Diazepam }\right.} \\
\text { Binding } \\
\text { (\% of Control) }\end{array}$ \\
\hline A & 1. None & 100 \\
\hline & 2. Ftazolate $(0.1 \mu \mathbf{M})$ & 113 \\
\hline & 3. Etazolate $(0.3 \mu \mathrm{M})$ & 122 \\
\hline & 4. Etazolate $(1 \mu \mathrm{M})$ & 146 \\
\hline & 5. Etazolate $(3 \mu \mathrm{M})$ & 175 \\
\hline & 6. Etazolate $(10 \mu \mathrm{M})$ & 182 \\
\hline & 7. Etazolate $(30 \mu \mathrm{M})$ & 150 \\
\hline B. & 1. None & 100 \\
\hline & 2. Etazolate $(10 \mu \mathrm{M})$ & 168 \\
\hline & 3. GABA $(10 \mu \mathrm{M})$ & 175 \\
\hline & 4. IAA $(100 \mu \mathrm{M})$ & 128 \\
\hline & 5. Etazolate $(10 \mu \mathrm{M})+$ GABA $(10 \mu \mathrm{M})$ & 228 \\
\hline & 6. Etazolate $(10 \mu \mathrm{M})+$ IAA $(100 \mu \mathrm{M})$ & 190 \\
\hline & $\begin{array}{l}\text { 7. Etazolate }(10 \mu \mathrm{M})+\text { GABA }(10 \mu \mathrm{M})+\text { IAA }(100 \\
\mu \mathrm{M})\end{array}$ & 201 \\
\hline C. & 1. None & 100 \\
\hline & 2. Pentobarbital $(100 \mu \mathrm{M})$ & 151 \\
\hline & 3. GABA $(50 \mu \mathrm{M})$ & 169 \\
\hline & 4. Pentobarbital $(100 \mu \mathrm{M})+\mathrm{GABA}(50 \mu \mathrm{M})$ & 228 \\
\hline D. & 1. None & 100 \\
\hline & 2. Etazolate $(5 \mu \mathrm{M})$ & 177 \\
\hline & 3. Pentobarbital (100 $\mu \mathrm{M})$ & 146 \\
\hline & 4. Bicuculline $(10 \mu \mathrm{M})$ & 86 \\
\hline & 5. THIP $(100 \mu \mathrm{M})$ & 89 \\
\hline & 6. Etazolate $(5 \mu \mathrm{M})+$ bicuculline $(10 \mu \mathrm{M})$ & 86 \\
\hline & 7. Pentobarbital $(100 \mu \mathrm{M})+$ bicuculline $(10 \mu \mathrm{M})$ & 108 \\
\hline & 8. Etazolate $(5 \mu \mathrm{M})+$ THIP $(100 \mu \mathrm{M})$ & 184 \\
\hline & 9. Pentobarbital $(100 \mu \mathrm{M})+$ THIP $(100 \mu \mathrm{M})$ & 144 \\
\hline & 10. Bicuculline $(10 \mu \mathrm{M})+$ THIP $(100 \mu \mathrm{M})$ & 75 \\
\hline & $\begin{array}{l}\text { 11. Etazolate }(5 \mu \mathrm{M})+\text { bicuculline }(10 \mu \mathrm{M})+\text { THIP } \\
(100 \mu \mathrm{M})\end{array}$ & 91 \\
\hline & $\begin{array}{l}\text { 12. Pentobarbital }(100 \mu \mathrm{M})+\text { bicuculline }(10 \mu \mathrm{M})+ \\
\text { THIP }(100 \mu \mathrm{M})\end{array}$ & 93 \\
\hline
\end{tabular}

$\mu \mathrm{M}$, enhancement $51 \%$; Table $\mathrm{IC}$ ) was additive with that of GABA $(50 \mu \mathrm{M}$, enhancement $69 \%$ alone, $128 \%$ with pentobarbital).

The Scatchard plots in Figure 2 further demonstrate this point and also show that the enhancement of diazepam binding by etazolate (as well as GABA and pentobarbital) involves a decrease in $K_{D}$ without a change in the number of binding sites, $B_{\max }$. Maximal etazolate (10 $\mu \mathrm{M})$ decreased the $K_{D}$ for $\left[{ }^{3} \mathrm{H}\right]$ diazepam binding to fresh washed rat cortex membranes from 2.33 to $1.2 \mathrm{~nm}$ (Fig. 2 , legend). GABA alone $(10 \mu \mathrm{M})$ reduced the control $K_{D}$ to $0.94 \mathrm{nM}$, and pentobarbital alone $(500 \mu \mathrm{M})$ reduced it to $0.86 \mathrm{nM}$. Etazolate and pentobarbital together decreased the $K_{D}$ to $0.91 \mathrm{nM}$ (slightly lower than etazolate alone, but not lower than pentobarbital alone); etazolate and GABA together lowered the $K_{D}$ to $0.66 \mathrm{~nm}$ (lower than either drug alone and about 3.5-fold over control).

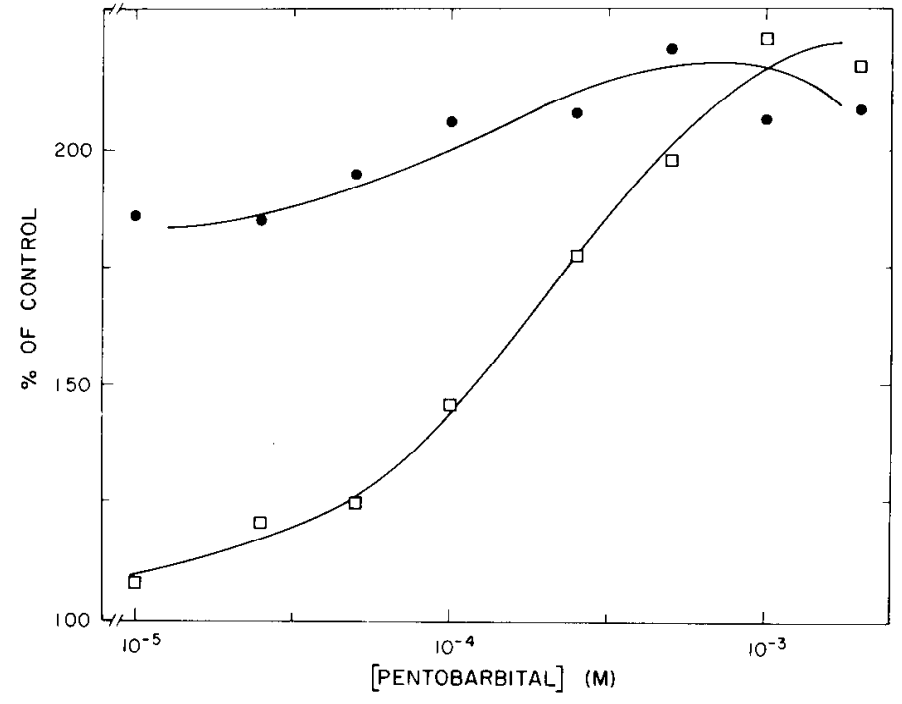

Figure 1. Enhancement of $\left[{ }^{3} \mathrm{H}\right]$ diazepam binding by pentobarbital in the presence and absence of etazolate. $\left[{ }^{3} \mathrm{H}\right]$ Diazepam binding was measured as described under "Materials and Methods" with $0.5 \mathrm{~nm}\left[{ }^{3} \mathrm{H}\right]$ diazepam, and varying concentrations of pentobarbital, with $(O)$ and without $(\square)$ constant etazolate (10 $\mu \mathrm{M})$. Each point is the average of triplicate determinations with variations of $\leq 5 \%$ and is typical of at least three experiments which varied by $\pm 10 \%$.

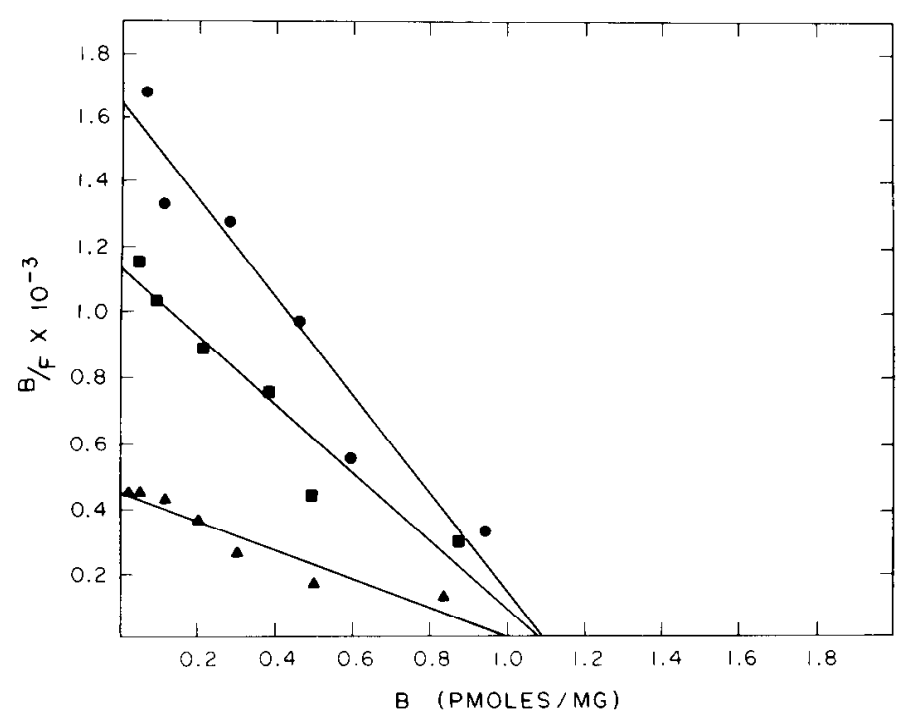

Figure 2. Scatchard plot of $\left[{ }^{3} \mathrm{H}\right]$ diazepam binding to rat cortex in the absence and presence of drugs. $\left[{ }^{3} \mathrm{H}\right]$ Diazepam concentrations were varied from 0.05 to $50 \mathrm{nM}$, determining nondisplaceable background with $10 \mu \mathrm{M}$ nonradioactive diazepam. Brain membranes were prepared as described under "Materials and Methods." $\Delta$, Control; $\square$, with $500 \mu \mathrm{M}$ pentobarbital and $10 \mu \mathrm{M}$ etazolate; , with $10 \mu \mathrm{M}$ GABA and $10 \mu \mathrm{M}$ etazolate. The solid lines represent computer-fitted linear regressions. The result is typical of five experiments. Kinetic constants ( $K_{D}$ (nanomolar concentrations) and $B_{\max }$ (picomoles per $\mathrm{mg}$ )) of presented data and additional controls are: control $(2.33,0.99)$; $10 \mu \mathrm{M}$ etazolate $(1.2,1.05) ; 500 \mu \mathrm{M}$ pentobarbital $(0.86,0.99) ; 10$ $\mu \mathrm{M}$ GABA $(0.94,1.06) ; 500 \mu \mathrm{M}$ pentobarbital and $10 \mu \mathrm{M}$ etazolate $(0.91,1.08) ; 10 \mu \mathrm{M}$ GABA and $10 \mu \mathrm{M}$ etazolate $(0.66,1.09) . B / F$, bound/free. 
Imidazole acetic acid (IAA) is a GABA mimetic able to stimulate benzodiazepine binding to a low but significant extent, but additionally, this drug will reverse the enhancement by GABA in a manner suggestive of partial agonists (Karobath et al., 1979; Braestrup et al., 1979). This drug was used to determine whether the effect of etazolate was independent of that of GABA. Saturating levels of IAA $(100 \mu \mathrm{M})$ reversed the effect of GABA, either in the absence or presence of etazolate, but did not affect the action of etazolate. The level of enhancement of benzodiazepine binding by a combined addition of IAA, etazolate, and GABA together was equal to the effect of etazolate and IAA in the absence of GABA (Table $\mathrm{I} B$ ). Another GABA analogue which does not enhance $\left[{ }^{3} \mathrm{H}\right.$ benzodiazepine binding but can reverse the effect of GABA is the compound THIP. This agent also failed to inhibit the etazolate or pentobarbital enhancement of benzodiazepine binding (Table $I D$ ). Thus, the action of etazolate appears different from that of GABA.

The GABA antagonist, bicuculline, inhibits GABAstimulated $\left[{ }^{3} \mathrm{H}\right]$ diazepam binding (Tallman et al., 1980; Karobath et al., 1979; Braestrup et al., 1979). This drug also inhibited stimulation of benzodiazepine binding by both pentobarbital and etazolate (Table $I D$ ). However, the GABA analogues, IAA and THIP, did not reverse the effects of pentobarbital or etazolate (Table $\mathrm{I} D$ ), indicating that the latter compounds do not act at the GABA receptor site. Assuming that bicuculline and IAA both act at the GABA receptor site, the bicuculline reversal of etazolate enhancement of diazepam binding must be indirect. High concentrations of IAA and THIP apparently did not reverse the action of bicuculline; however, a dose-response curve for the bicuculline effect (Fig. 3) revealed that bicuculline was very potent and present in concentrations greatly exceeding its $\mathrm{IC}_{50}$ value in the experiments described in Table I. Bicuculline at 10 to 100 nM inhibited the enhancement of benzodiazepine binding by GABA, etazolate, and pentobarbital (Fig. 3). However, the inhibition by bicuculline of pentobarbital enhancement, but not that of GABA or etazolate, did not reach $100 \%$ but leveled out at about $70 \%$ reversal (four experiments) under these conditions. The plateau effect is not yet understood completely but again is consistent with an indirect interaction between the binding sites for bicuculline and pentobarbital.

The stimulation of $\left[{ }^{3} \mathrm{H}\right]$ diazepam binding by etazolate was inhibited by picrotoxinin in a dose-dependent manner, with $50 \%$ inhibition at $6 \mu \mathrm{M}(5 \pm 3 \mu \mathrm{M}, n=3)$ (Fig. 4). Tetramethylenedisulfotetramine (TETS) and RO5-3663, two convulsants known to act at the picrotoxinin binding site (Olsen et al., 1980; Ticku and Olsen, 1979; LeebLundberg et al., 1981), also inhibited etazolate-enhanced benzodiazepine binding (Table II). Due to an additional inhibition of base line diazepam binding, it was difficult to establish accurate $\mathrm{IC}_{50}$ values for the inhibition by these compounds. The experiments described in Table II were carried out with frozen-thawed, thoroughly washed membranes to minimize the endogenous GABA content. The harsher treatment resulted in a smaller but still significant ( $38 \pm 5 \%, n=4$ ) enhancement by $10 \mu \mathrm{M}$ etazolate than that seen with fresh rat cortex.

Etazolate displaced specific $\alpha-\left[{ }^{3} \mathrm{H}\right]$ dihydropicrotoxinin (DHP) binding (Fig. 5). This inhibitory property was

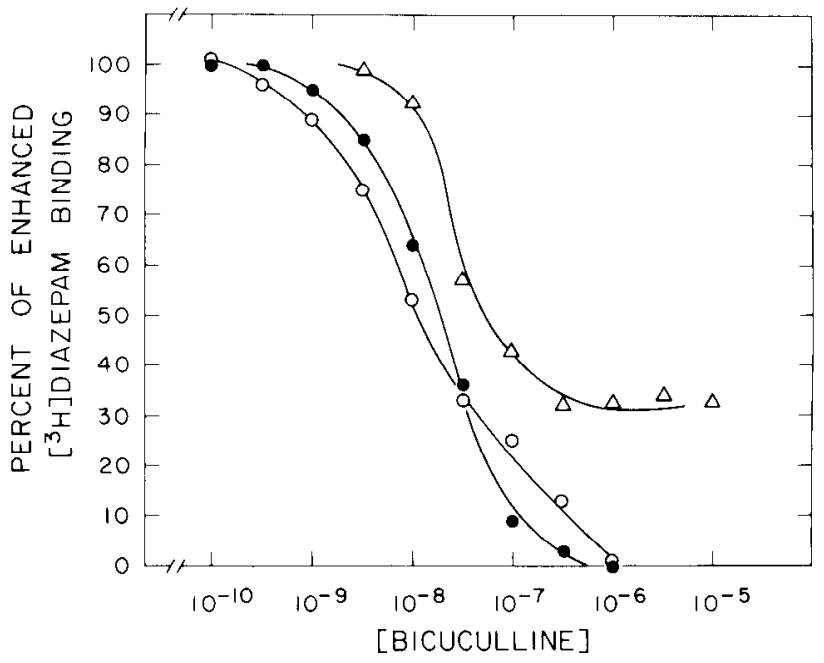

Figure 3. Concentration dependence of bicuculline reversal of benzodiazepine binding enhancement by various agents. Rat cortex membranes were prepared and assayed as described under "Materials and Methods" with constant $\left[{ }^{3} \mathrm{H}\right]$ diazepam at $0.5 \mathrm{nM}$. The enhancement of benzodiazepine binding by $10 \mu \mathrm{M}$ etazolate (O), $10 \mu \mathrm{M}$ GABA (O), and $100 \mu \mathrm{M}$ pentobarbital $(\triangle)$ was determined in the absence and presence of varying concentrations of bicuculline (diluted into the assays from a $5 \mathrm{~mm}$ stock solution at $\mathrm{pH} 3$ just prior to addition of the membrane suspension). The enhancement over base line benzodiazepine binding by the three drugs was normalized to $100 \%$ and was aclually equal to $68 \%$ (elazolate), $71 \%$ (GABA), and $55 \%$ (pentobarbital). Each point is the mean of triplicates which varied by $<10 \%$, and each result is typical of at least four experiments. The $\mathrm{IC}_{50}$ values for bicuculline reversal of drug enhancement were 11,19 , and $30 \mathrm{nM}$, respectively.

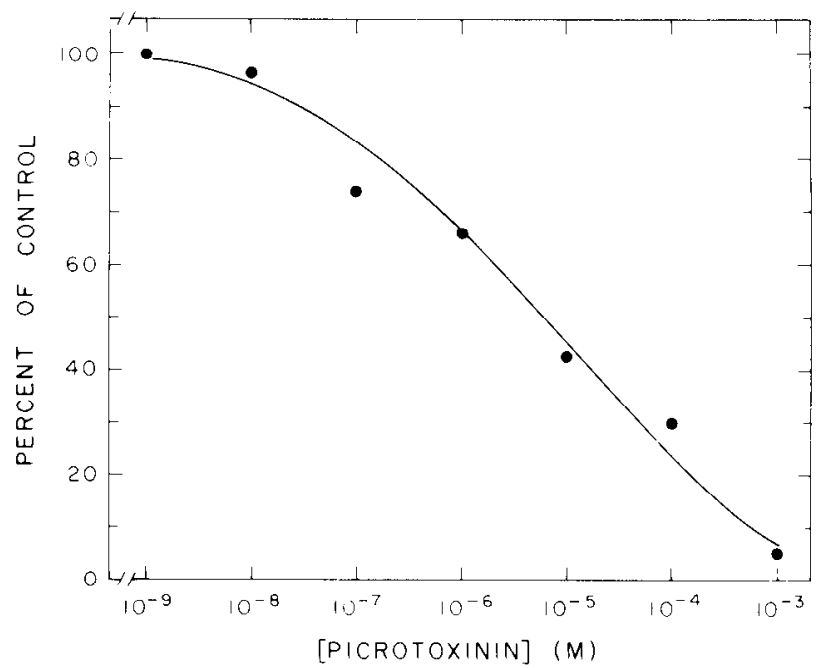

Figure 4. Inhibition by picrotoxinin of etazolate-enhancement of $\left[{ }^{3} \mathrm{H}\right]$ diazepam binding. Membranes were prepared and assayed as described under "Materials and Methods" with a constant concentration $(10 \mu \mathrm{M})$ of etazolate and various concentrations of picrotoxinin. The experiment is typical of three trials, and the $\mathrm{IC}_{50}$ value was $6 \mu \mathrm{M}$.

shared with the somewhat more potent pyrazolopyridine, cartazolate. Etazolate and cartazolate inhibited [ $\left.{ }^{3} \mathrm{H}\right] \mathrm{DHP}$ binding with $50 \%$ displacement at $8 \pm 3 \mu \mathrm{M}$ and $0.5 \pm 0.2$ $\mu \mathrm{M}(n=3)$, respectively. Figure 6 shows a double reciprocal plot of $\left[{ }^{3} \mathrm{H}\right] \mathrm{DHP}$ binding with and without etazo- 


\section{TABLE II}

Interaction of picrotoxin-like convulsants with pyrazolopyridine enhancement of benzodiazepine binding

Rat brain membranes (fraction $\mathrm{P}_{2}+\mathrm{P}_{3}$ ) were prepared by freezing and thawing and five buffer washes $(20 \mathrm{~mm}$ sodium phosphate, $0.2 \mathrm{M}$ $\mathrm{NaCl}$, pH $7.0 \pm 0.1)$. [ $\left.{ }^{3} \mathrm{H}\right]$ Diazepam binding was done as described under "Materials and Methods" using $0.5 \mathrm{~nm}\left[{ }^{3} \mathrm{H}\right]$ diazepam. Each number is typical of at least two determinations in triplicate which varied by $<10 \%$. The names and sources of all drugs are given in the text.

\begin{tabular}{lc}
\hline \multicolumn{1}{c}{ Additions } & $\begin{array}{c}\text { ["H]Diazepam } \\
\text { Binding } \\
\text { (\% of Control) }\end{array}$ \\
\hline 1. None & 100 \\
2. Etazolate $(10 \mu \mathrm{M})$ & 133 \\
3. TETS $(0.05 \mu \mathrm{M})$ & 99 \\
4. TETS $(0.5 \mu \mathrm{M})$ & 98 \\
5. TETS $(5 \mu \mathrm{M})$ & 97 \\
6. TETS $(50 \mu \mathrm{M})$ & 76 \\
& \\
7. RO5-3663 $(0.1 \mu \mathrm{M})$ & 99 \\
8. RO5-3663 $(1 \mu \mathrm{M})$ & 99 \\
9. RO5-3663 $(10 \mu \mathrm{M})$ & 91 \\
10. RO5-3663 $(100 \mu \mathrm{M})$ & 57 \\
& \\
11. Etazolate $(10 \mu \mathrm{M})+$ TETS $(0.05 \mu \mathrm{M})$ & 127 \\
12. Etazolate $(10 \mu \mathrm{M})+$ TETS $(0.5 \mu \mathrm{M})$ & 124 \\
13. Etazolate $(10 \mu \mathrm{M})+$ TETS $(5 \mu \mathrm{M})$ & 121 \\
14. Etazolate $(10 \mu \mathrm{M})+$ TETS $(50 \mu \mathrm{M})$ & 98 \\
15. Etazolate $(10 \mu \mathrm{M})+$ RO5-3663 $(0.1 \mu \mathrm{M})$ & 127 \\
16. Etazolate $(10 \mu \mathrm{M})+$ RO5-3663 $(1 \mu \mathrm{M})$ & 119 \\
17. Etazolate $(10 \mu \mathrm{M})+$ RO5-3663 $(10 \mu \mathrm{M})$ & 112 \\
18. Etazolate $(10 \mu \mathrm{M})+$ RO5-3663 $(100 \mu \mathrm{M})$ & 82 \\
\hline
\end{tabular}

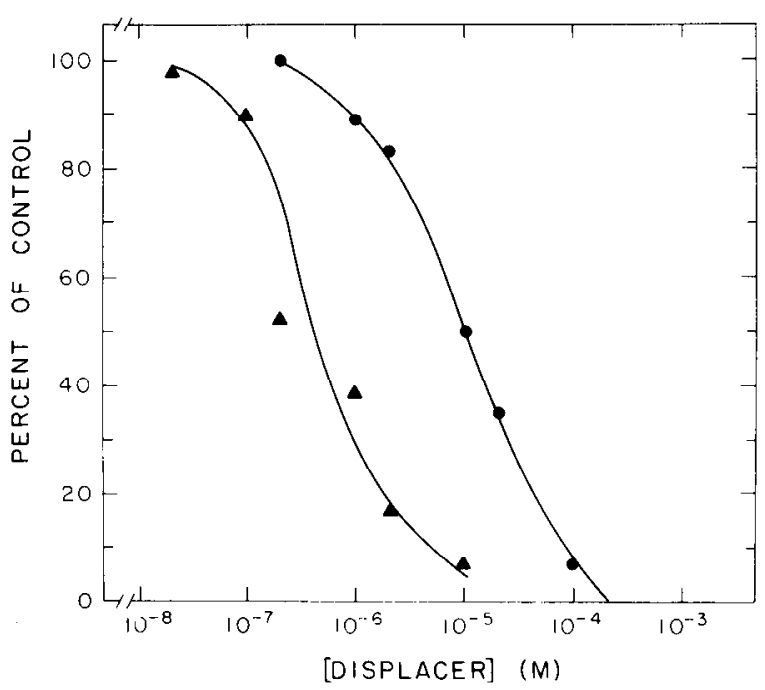

Figure 5. Displacement of specific. DHP hinding by etazolate (SQ20009) and cartazolate (SQ65396). Membranes were prepared and assayed as described under "Materials and Methods" without and with various concentrations of displacing agents. - Etazolate; $\boldsymbol{\Delta}$, cartazolate. The experiments are typical of three trials, and the $\mathrm{IC}_{50}$ values were 10 and $0.4 \mu \mathrm{M}$, respectively.

late, suggesting a competitive type of inhibition. These results, taken together, suggest that the pyrazolopyridines perturb benzodiazepine binding via picrotoxinin/ barbiturate receptor sites, which may be coupled to, but are distinct from, GABA receptor sites.

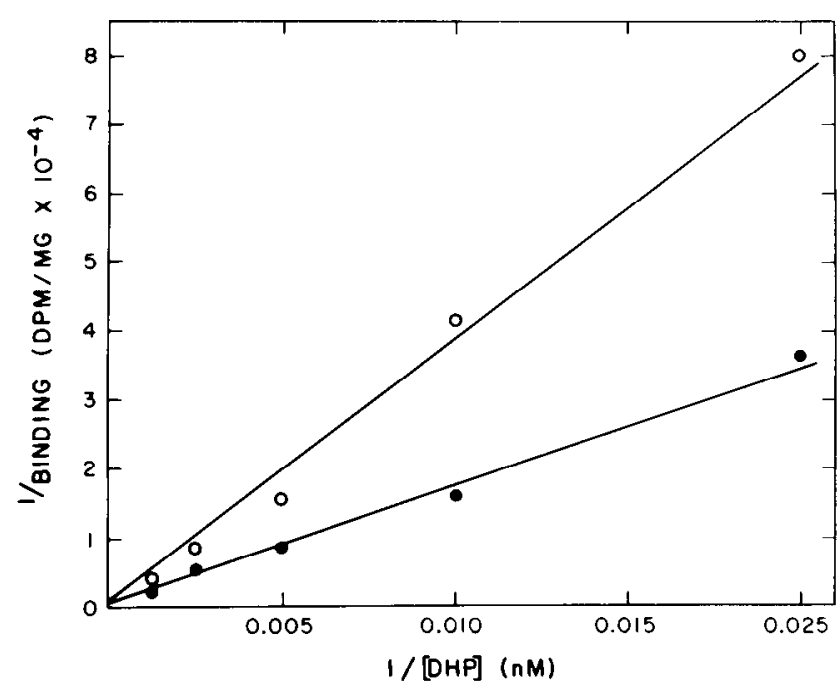

Figure 6. Competitive inhibition of specific DHP binding by etazolate. Rat cortex membranes were prepared and assayed for $\left[{ }^{3} \mathrm{H}\right] \mathrm{DHP}$ binding as described under "Materials and Methods." The concentration of DHP was varied from $10 \mathrm{nM}$ to 10 $\mu \mathrm{M}$ with (O) and without (O) etazolate at $10 \mu \mathrm{M}$, and the data are shown as a Lineweaver-Burk plot. The apparent $K_{D}$ for the single class of DHP binding sites was $1 \mu \mathrm{M}$ and the apparent $K_{I}$ for the competitive inhibitor etazolate was $10 \mu \mathrm{M}$.

\section{Discussion}

Etazolate recently has been found to have potent stimulatory effects on benzodiazepine binding, an action which might be related to its pharmacological properties (Beer et al., 1978; Williams and Risley, 1979; Supavilai and Karobath, 1980). The modulatory role of barbiturates on benzodiazepine binding recently has been characterized in this laboratory (Leeb-Lundberg et al., 1980). Etazolate and pentobarbital appear to have a very similar mechanism of action in this in vitro system, at least in part. Maximal concentrations of pentobarbital could elevate further etazolate enhancement of benzodiazepine binding up to the level of the maximal effect of pentobarbital. This elevation by the two drugs together was not fully additive, however, never surpassing the maximal effect of pentobarbital alone. This suggests that the two compounds have a common action, although with different maximal effects.

Under our conditions, the in vitro effect of etazolate seems to be different from the enhancement of benzodiazepine binding by GABA. The enhancement by either etazolate or pentobarbital was additive with that of GABA. In addition, the GABA analogue, IAA, was able to reverse the stimulatory effects of GABA, both with and without etazolate present, but IAA did not disturb the etazolate enhancement, either alone or with GABA present. Likewise, the GABA analogue, THIP, reversed the action of GABA but not that of etazolate or pentobarbital.

Bicuculline is able to inhibit GABA- as well as etazolate- and pentobarbital-enhanced benzodiazepine binding. Therefore, it could very well be argued that these two exogenous ligands stimulate benzodiazepine binding simply by increasing the sensitivity of the GABA-benzodiazepine receptor coupling. However, etazolate enhancement is still observed in membranes which have 
been thoroughly washed to remove endogenous GABA. Furthermore, any influence from the GABA receptor site would be blocked by IAA or THIP, but these drugs do not disturb etazolate or pentobarbital enhancement. Additionally, hicuculline fails to reverse pentobarbital enhancement completely even at $10 \mu \mathrm{M}$, although, at $30 \mathrm{~nm}$, it inhibits a large portion of the pentobarbital effect (Fig. 3 ). This partial effect indicates that at least some of the pentobarbital sites are not identical with bicuculline sites. That fraction of pentobarbital-enhanced benzodiazepine binding which is blocked by bicuculline probably corresponds to a subpopulation of benzodiazepine receptors which are allosterically coupled to bicuculline (GABA receptor?) sites. These bicuculline-sensitive sites also appear to be perturbed by etazolate, but the bicucullineinsensitive sites which are enhanced by pentobarbital are not perturbed by etazolate. Nevertheless, the effect which etazolate has on benzodiazepine binding resembles more the effect of pentobarbital than that of GABA.

The potency of bicuculline in these experiments is somewhat greater than previously reported for inhibition of GABA binding (Olsen et al., 1978) or GABA enhancement of benzodiazepine binding (Braestrup et al., 1979) and appears to be dependent on brain region and on a high concentration $(>0.1 \mathrm{M})$ of chloride ions ( $F$. LeebLundberg, A. Snowman, and R. W. Olsen, unpublished data). Some anions are known to enhance the affinity of bicuculline for GABA receptor sites (Möhler and Okada, 1978). The apparent inability of $100 \mu \mathrm{M}$ THIP or IAA to reverse the effects of $10 \mu \mathrm{M}$ bicuculline is probably due to the high potency of bicuculline under these conditions. Alternatively, bicuculline might act at yet another drug binding site distinct from the GABA receptors (IAA and THIP binding sites).

Neither etazolate nor pentobarbital appears to act even indirectly via the GABA recognition site. The results presented here strongly suggest that the primary site of action of etazolate is a site related to the picrotoxininsensitive chloride ion channel. The effect of etazolate, like that of pentobarbital, could be completely and competitively blocked (Leeb-Lundberg et al., 1980) by picrotoxinin in a dose-dependent manner (Fig. 4) and with a potency correlating well with the affinity for $\left[{ }^{3} \mathrm{H}\right] \mathrm{DHP}$ binding sites, considering that saturating levels of etazolate had to be displaced (Leeb-Lundberg and Olsen, 1980; Olsen and Leeb-Lundberg, 1981; Olsen, 1981). The picrotoxin reversal of etazolate enhancement of benzodiazepine binding, which was shown initially by Supavilai and Karobath (1979), provides the first link between the picrotoxinin and benzodiazepine receptors. Picrotoxin does not inhibit GABA enhancement of benzodiazepine binding (Tallman et al., 1980). Both etazolate (Supavilai and Karobath, 1979) and pentobarbital (Leeb-Lundberg et al., 1980) effects were dependent on anions and specific for those anions that are able to penetrate GABA-activated chloride ion channels. This phenomenon of anion dependence, likewise, is not shared by GABA, at least not to the same extent (F. Leeb-Lundberg, A. Snowman, and $\mathrm{R}$. W. Olsen, unpublished data).

The stimulatory effect of etazolate was inhibited also by the cage convulsant, TETS, and the convulsant benzodiazepine, RO5-3663, two drugs previously reported to act at the picrotoxinin binding site (Olsen et al., 1980;
'Ticku and Olsen, 1979; Leeb-Lundberg et al., 1981; LeebLundberg and Olsen, 1980; Olsen and Leeb-Lundberg, 1981). Further evidence for an interaction with a picrotoxinin-sensitive site by the pyrazolopyridines comes from the evidence that both etazolate and cartazolate inhibit $\left[{ }^{3} \mathrm{H}\right] \mathrm{DHP}$ binding in a competitive manner and with potencies correlating well with their potencies for stimulating benzodiazepine binding. Pentobarbital has been shown previously (Ticku and Olsen, 1978) to inhibit DHP binding in a competitive manner with a potency $\left(K_{I}=50 \mu \mathrm{M}\right)$ which also agrees with its effective concentration ( $\mathrm{EC}_{50}=100 \mu \mathrm{M}$ ) for enhancing benzodiazepine binding (Leeb-Lundberg et al., 1980). The latter action of a series of barbiturates has been demonstrated to correlate well with pharmacological activity for these drugs.

Earlier studies found no direct interaction between picrotoxinin and GABA receptor binding (Olsen et al., 1978), but recent studies show that GABA binding can be perturbed by drugs which bind to picrotoxinin-sensitive sites, namely, pentobarbital (Johnston and Willow, 1981; Olsen, 1981) and etazolate (Placheta and Karobath, 1980). Furthermore, barbiturates (Skolnick et al., 1980) and etazolate (Supavilai and Karobath, 1980) enhance, while the convulsant benzodiazepine (RO5-3663) reverses (O'Brien and Spirt, 1980) the ability of GABA to enhance benzodiazepine binding; GABA analogues enhance the ability of etazolate to enhance benzodiazepine binding (Supavilai and Karobath, 1980). Therefore, at least some GABA and picrotoxinin binding sites appear to be coupled in the membrane via a complex interaction involving some benzodiazepine receptors.

Interestingly, both benzodiazepine (Tallman et al., 1980) and picrotoxinin binding sites (Olsen et al., 1980; Olsen and Leeb-Lundberg, 1980) are inhibited by high concentrations of some naturally occurring purines and related compounds, and these agents also allosterically perturb GABA receptor binding (Ticku and Burch, 1980). Benzodiazepines at micromolar concentrations inhibit picrotoxinin binding (Olsen et al., 1980; Leeb-Lundberg et al., 1981). Although the picrotoxinin binding sites and high affinity benzodiazepine binding sites appear distinct on specificity grounds, these effects may represent further examples of allosteric interaction between the two populations.

Obviously there are more complicated interactions occurring at the GABA/benzodiazepine receptor complex than can be solved by a simple two-unit model. The evidence suggests a coupling between at least three drug receptors: those for GABA, benzodiazepines, and picrotoxinin. At least two types of drugs can interact at the picrotoxinin-sensitive site. One class of drugs (like etazolate and pentobarbital) is able to enhance the affinity for benzodiazepines. A second class of drugs (like picrotoxinin and related convulsants) will not affect the affinity of benzodiazepines but will rather block the effects of the former class of drugs.

\section{References}

Beer, B., C. A. Klepner, A. S. Lippa, and R. F. Squires (1978) Enhancement of ${ }^{3} \mathrm{H}$-diazepam binding by SQ 65396: A novel anti-anxiety agent. Pharmacol. Biochem. Behav. 9: 849-851. 
Braestrup, C., M. Nielsen, P. Krogsgaard-Larsen, and E. Falch (1979) Partial agonists for brain GABA/benzodiazepine receptor complex. Nature 280: 331-333.

Costa, E., and A. Guidotti (1979) Molecular mechanisms in the receptor action of benzodiazepines. Annu. Rev. Pharmacol. Toxicol. 19: 531-545.

Costa, T., D. Rodbard, and C. B. Pert (1979) Is the benzodiazepine receptor coupled to a chloride anion channel? Nature 277: 315-317.

Haefely, W., P. Polc, R. Schaffner, H. H. Keller, L. Pieri, and H. Möhler (1979) Facilitation of GABAergic transmission by drugs. In GABA-Neurotransmitters, P. Krogsgaard-Larsen, J. Scheel-Kruger, and H. Kofod, eds., pp. 357-375, Munksgaard, Copenhagen.

Johnston, G. A. R., and M. Willow (1981) Barbiturates and GABA receptors. In GABA and Benzodiazepine Receptors, E. Costa, G. DiChiara, and G. Gessa, eds., pp. 191-198, Raven Press, New York.

Karobath, M., R. Placheta, M. Lippitsch, and P. KrogsgaardLarsen (1979) Is stimulation of benzodiazepine binding mediated by a novel GABA receptor? Nature 278: 748-749.

Leeb-Lundberg, F., and R. W. Olsen (1980) Picrotoxinin binding as a probe of the GABA postsynaptic membrane receptorionophore complex. In Psychopharmacology and Biochemistry and Neurotransmitter Receptors, H. I. Yamamura, R. W. Olsen, and E. Usdin, eds., pp. 593-606, Elsevier, New York.

Leeb-Lundberg, F., A. Snowman, and R. W. Olsen (1980) Barbiturate receptor sites are coupled to benzodiazepine receptors. Proc. Natl. Acad. Sci. U. S. A. 77: 7468-7472.

Leeb-Lundberg, F., C. Napias, and R. W. Olsen (1981) Dihydropicrotoxinin binding sites in mammalian brain: Interactions with convulsant and depressant benzodiazepines. Brain Res., in press.

Möhler, H., and T. Okada (1977) Benzodiazepine receptors: Demonstration in the central nervous system. Science 198: 849-851.

Möhler, H., and T. Okada (1978) Properties of $\gamma$-aminobutyric acid receptor binding with $(+)-\left[{ }^{3} \mathrm{H}\right]$ bicuculline methiodide in rat cerebellum. Mol. Pharmacol. 14: 256-265.

Napias, C., M. O. Bergman, P. C. Van Ness, D. V. Greenlee, and R. W. Olsen (1980) GABA binding in mammalian brain: Inhibition by endogenous GABA. Life Sci. 27: 1001-1011.

O'Brien, R. A., and N. M. Spirt (1980) The inhibition of GABAstimulated benzodiazepine binding by a convulsant benzodiazepine. Life Sci. 26: 1441-1445.

Olsen, R. W. (1981) The GABA postsynaptic membrane receptor-ionophore complex: Site of action of convulsant and anticonvulsant drugs. Mol. Cell. Biochem., in press.

Olsen, R. W., and F. Leeb-Lundberg (1980) Endogenous inhib- itors of picrotoxinin-convulsant binding sites in rat brain. Eur. J. Pharmacol. 65: 101-104.

Olsen, R. W., and F. Leeb-Lundberg (1981) Convulsant and anticonvulsant drug binding sites related to GABA-regulated chloride ion channels. In GABA and Benzodiazepine Receptors, E. Costa, D. DiChiara, and G. Gessa, eds., pp. 93-102, Raven Press, New York.

Olsen, R. W., M. K. Ticku, P. C. Van Ness, and D. Greenlee (1978) Effects of drugs on $\gamma$-aminobutyric acid receptors, uptake, release and synthesis in vitro. Brain Res. 139: 277294.

Olsen, R. W., F. Leeb-Lundberg, and C. Napias (1980) Picrotoxinin and convulsant binding sites in mammalian brain. Brain Res. Bull. 5 (Suppl. 2): 217-221.

Placheta, P., and M. Karobath (1980) In vitro modulation by SQ 20009 and SQ 65396 of GABA receptor binding in rat CNS membranes. Eur. J. Pharmacol. 62: 225-228.

Salama, A. I., and B. A. Meiners (1980) Enhancement of benzodiazepine binding by the novel anxiolytic ICI 136,753. Soc. Neurosci. Abstr. 6: 190.

Skolnick, P., S. M. Paul, and J. L. Barker (1980) Pentobarbital potentiates GABA-enhanced ${ }^{3} \mathrm{H}$-diazepam binding to benzodiazepine receptors. Eur. J. Pharmacol. 65: 125-127.

Squires, R. F., and C. Braestrup (1977) Benzodiazepine receptors in rat brain. Nature 266: 732-734.

Supavilai, P., and M. Karobath (1979) Stimulation of benzodiazepine receptor binding by SQ 20009 is chloride-dependent and picrotoxin-sensitive. Eur. J. Pharmacol. 60: 111-113.

Supavilai, P., and M. Karobath (1980) Interaction of SQ 20009 and GABA-like drugs as modulators of benzodiazepine receptor binding. Eur. J. Pharmacol. 62: 229-233.

Tallman, T. F., S. M. Paul, P. Skolnick, and D. W. Gallager (1980) Receptors for the age of anxiety: Pharmacology of the benzodiazepines. Science 207: 274-281.

Ticku, M. K., and T. Burch (1980) Purine inhibition of $\left[{ }^{3} \mathrm{H}\right] \gamma$ aminobutyric acid receptor binding to rat brain membranes. Biochem. Pharmacol. 29: 1217-1220.

Ticku, M. K., and R. W. Olsen (1978) Interaction of barbiturates with dihydropicrotoxinin binding sites related to the GABA receptor-ionophore system. Life Sci. 22: 1643-1652.

Ticku, M. K., and R. W. Olsen (1979) Cage convulsants inhibit picrotoxinin binding. Neuropharmacology 18: 315-318.

Ticku, M. K., M. Ban, and R. W. Olsen (1978) Binding of $\left[{ }^{3} \mathrm{H}\right] \alpha$-dihydropicrotoxinin, a $\gamma$-aminobutyric acid synaptic antagonist, to rat brain membranes. Mol. Pharmacol. 14: 391-402.

Williams, M., and E. A. Risley (1979) Enhancement of the binding of ${ }^{3} \mathrm{H}$-diazepam to rat brain membranes in vitro by SQ 20009, a novel anxiolytic, $\gamma$-aminobitutyric acid (GABA) and muscimol. Life Sci. 24: 833-842. 